\title{
Comunicação digital na gestão pública dos municípios da RMVP: acesso à informação, transparência e mecanismos de participação
}

Moacir José dos Santos

Programa de Pós-Graduação em Planejamento e Desenvolvimento Regional da Universidade de Taubaté

(UNITAU)

Monica Franchi Carniello

Programa de Pós-Graduação em Planejamento e Desenvolvimento Regional da Universidade de Taubaté

(UNITAU)

Edson Aparecida de Araújo Querido Oliveira

Programa de Pós-Graduação em Planejamento e Desenvolvimento Regional da Universidade de Taubaté

(UNITAU)

Recebido: 10/10/2012 Versão revisada (entregue): 18/03/2013 Aprovado: 24/03/2013

\section{Resumo}

A realização do desenvolvimento sustentável corresponde à consolidação e aplicação dos princípios pertinentes à democracia, particularmente quanto à transparência da gestão pública. Partindo da premissa de que na estrutura da gestão pública brasileira os municípios são o primeiro elo entre os cidadãos e o poder público, o artigo apresenta uma análise sobre como os municípios têm disponibilizado informações sobre a gestão pública à sociedade por meio da comunicação digital. Para isso, foi realizada uma pesquisa de caráter exploratório-descritivo, com coleta de dados bibliográfica e documental, em municípios da Região Metropolitana do Vale do Paraíba. Verificou-se que há grandes disparidades entre os municípios no uso da obrigatoriedade legal de disponibilização de informações sobre gestão pública aos cidadãos. Enquanto alguns apenas cumprem o mínimo previsto em lei, outros fazem da obrigatoriedade de disponibilizar informação um meio facilitador de prestação de serviço ao cidadão, um canal de comunicação que fomenta o diálogo entre sociedade e poder público, fundamento da democracia participativa. Tal cenário permite traçar a hipótese de que um dos caminhos para favorecer o desenvolvimento sustentável, fundado na transparência da gestão pública local, passa por ações de capacitação dos gestores municipais por parte das outras instâncias de governo (estadual e federal).

Palavras-chave | Comunicação digital; gestão pública; participação política; região metropolitana; transparência.

Código JEL | H70; O38; R58. 


\title{
DIGITAL COMMUNICATION IN PUBLIC MANAGEMENT OF MUNICIPALITIES OF THE RMVP: ACESS TO INFORMATION, TRANSPARENCY AND PARTICIPATION MECHANISMS
}

\begin{abstract}
The realization of sustainable development corresponds to the consolidation and implementation of the relevant principles of democracy, particularly as to the transparency of public management. Assuming that in the structures of Brazilian public administration municipalities are considered the first link between citizens and the government, this paper presents an analysis of how municipalities have provided information on public management to society through digital communication. For that, an exploratory-descriptive survey was conducted with bibliographical and documentary data collection, in cities of the Paraíba Valley. It was found that there are large disparities among municipalities in the use of the legal prerogative of providing information about public administration to citizens. While some only meet the minimum required by law, others make mandatory information available as a means of facilitating service delivery to citizens, a communication channel that fosters the dialogue between society and government, founded in a participatory democracy. This scenario allows tracing the hypothesis that one of the ways to encourage sustainable development, based on the transparency of local public administration, undergoes training activities of municipal managers on the part of other government levels (state and federal).
\end{abstract}

Keywords | Digital communications; public administration; political participation; metropolitan area; transparency.

JEL-Code | H70; O38; R58.

\section{COMUNICACIÓN DIGITAL EN LA GESTIÓN PÚBLICA DE MUNICIPIOS DE LA RMVP: ACCESO A LA INFORMACIÓN, TRANSPARENCIA Y MECANISMOS DE PARTICIPACIÓN}

\section{Resumen}

La realización de un desarrollo sostenible corresponde a la consolidación y puesta en práctica de principios pertinentes a la democracia, en particular en cuanto a la transparencia de la gestión pública. A partir de la premisa de que en la estructura de la administración pública brasileña las municipalidades son el primer vínculo entre los ciudadanos y el gobierno, el documento presenta un análisis de cómo los municipios han proporcionado información sobre la gestión pública a la sociedad a través de la comunicación digital. Para ello, se realizó una investigación exploratoria y descriptiva con datos de fuentes bibliográficas y documentales en los municipios de conforman la Región Metropolitana del Valle del Paraíba. Se ha encontrado que existen grandes disparidades entre las municipalidades en el uso de la obligatoriedad legal de proporcionar información acerca de la administración pública a los ciudadanos. Mientras que en algunos sólo se cumple con el mínimo requerido por la ley, otros tornan la obligación de publicar información un medio facilitador de la oferta de servicios al ciudadano y un canal de comunicación que fomenta el diálogo entre sociedad y poder público, fundamento de la democracia participativa. Este escenario permite trazar la hipótesis de que una de las maneras de fomentar el desarrollo sostenible, basado en la transparencia de la administración pública local, es realizar acciones de capacitación de los gestores municipales por parte de los otros niveles de gobierno (estatal y federal). 
Palabras-clave | Comunicación digital; administración pública; participación política; zona metropolitana; transparencia.

Código JEL | H70; O38; R58.

\section{Introdução}

O presente artigo toma como referência o conceito de desenvolvimento como uma articulação entre os aspectos econômicos, ambientais e sociais, rompendo com a sinonímia entre desenvolvimento e crescimento econômico. Esse posicionamento torna necessário abordar os aspectos que viabilizam a condução do desenvolvimento e sua articulação com os modelos de gestão pública vigentes.

No modelo político brasileiro, pautado na redemocratização representada pela Constituição de 1988, é visível a instrumentalização da gestão pública, com ênfase na autonomia dos municípios, para o exercício da democracia participativa, ao formalizar os mecanismos de participação da sociedade. Ainda que o alcance dos resultados e das práticas participativas seja gradual e resultado de um constructo social que exige mudança paradigmática e de hábitos culturais, o marco legal é um aspecto relevante, uma vez que reflete o pressuposto político conceitual do país. O Estatuto da Cidade (2001) é um dos marcos legais que objetiva estimular um novo padrão de execução de políticas públicas no âmbito municipal ao responsabilizar os municípios quanto à gestão participativa. A afirmação do Estatuto da Cidade institucionalizou o envolvimento ativo dos cidadãos na gestão dos municípios brasileiros.

Para o exercício pleno da democracia participativa, tem-se como prerrogativa a disponibilização de informações aos cidadãos, conforme ressalta Sen (2000), ao afirmar que o acesso e o direito à informação é elemento essencial para o desenvolvimento. O cenário midiático contemporâneo, caracterizado pela comunicação digital estruturada em rede e conectado em escala global, é ambiente favorável para a disponibilização de informações à sociedade e para o estabelecimento de diálogo mais próximo entre governo e cidadão, uma vez que os fluxos de comunicação são de mão dupla. Tal aspecto pode ser um instrumental relacionado à gestão pública.

Em tempos de globalização, cidades do mundo inteiro estão desafiadas por profundas mudanças sociais, econômicas e políticas. As transformações recentes requerem novos modelos de gestão inovadores, assim como novos instrumentos, procedimentos e formas de ação, a fim de permitir que os administradores públicos tratem as mudanças de uma sociedade globalizada (REZENDE; FREY; BETINI, $\mathrm{s} / \mathrm{d})$. 
A maneira como se dá essa comunicação entre governo e munícipes é o objeto de estudo desse trabalho. $\mathrm{O}$ artigo tem como objetivo apresentar uma análise sobre como os 39 municípios da Região Metropolitana do Vale do Paraíba - SP, Brasil, têm disponibilizado informações sobre a gestão pública à sociedade por meio da comunicação digital, de maneira a verificar se o uso da comunicação digital reforça os preceitos da democracia participativa característica do panorama legal da gestão pública municipal brasileira.

Para conduzir o estudo, partiu-se da premissa de que o acesso à informação sobre a gestão pública é um direito da sociedade, visto que a instrumentaliza para a ação e participação. Em um ambiente midiático que favorece o amplo acesso à informação, caracterizado pelo sistema de comunicação digital em rede, e pela consolidação de uma legislação que prega a transparência da gestão pública, formulou-se a seguinte hipótese: o uso da comunicação digital pelos municípios da Região Metropolitana do Vale do Paraíba ocorre de maneira muito heterogênea no que tange à disponibilização de informações sobre a gestão pública, oferta de serviços ao munícipe e mecanismos de interação, fato que replica as evidentes desigualdades existentes entre os municípios e dificulta o exercício da democracia participativa.

\section{Comunicação governamental no contexto da comunicação digital}

A comunicação da administração municipal é uma característica intimamente conectada à democracia e, em um contexto comunicacional baseado na linguagem digital organizada em uma rede de alcance mundial, multiplica suas potencialidades de conexão com os munícipes. Essa afirmação decorre do pressuposto que a administração municipal dedicada ao desenvolvimento local sustentável, que incorpora os princípios da promoção da equidade social e do uso não predatório dos recursos naturais e econômicos, busca ampliar significativamente os canais de comunicação entre os gestores e a população, contribuindo para a ampliação e a consolidação da democracia participativa.

Destarte, nota-se uma vinculação entre os fundamentos da estrutura organizacional da comunicação contemporânea com os referenciais que pautam a democracia. A substituição de um modelo predominantemente unidimensional de comunicação, específico da comunicação de massa, que foi o modelo majoritário no período precedente à digitalização das mídias, por analogia se parece com modelos políticos fundados na concentração do poder no cume da hierarquia administrativa, com restrito envolvimento dos cidadãos nos processos decisórios. Porém, em uma sociedade progressivamente assentada na cultura digital, o aspecto norteador é a acessibilidade aos meios de produção e distribuição de mensagens por parte de usuários comuns. Esse cenário é absolutamente distinto do cenário 
anterior, no qual a produção e a distribuição dos conteúdos concentravam-se significativamente nas empresas de mídia.

A renovação do processo de produção, distribuição e consumo de informação e entretenimento a partir do ambiente digital tem impacto significativo nas experiências sociais. As novas possibilidades que emergem deste contexto não podem ser ignoradas quanto ao surgimento de possibilidades inéditas para a articulação da participação política capaz de pautar gestões municipais mais democráticas. Esse cenário impacta consideravelmente na gestão das cidades.

A aplicação das ferramentas de comunicação digital na administração pública municipal produz possibilidades antes inimagináveis. As cidades podem ampliar suas possibilidades significativamente, processo denominado por autores que investigam os fluxos comunicacionais como marketing de lugares. Esse posicionamento é propugnado por Kotler et al. (2005), que discute a aplicação do instrumental do marketing para a projeção de municípios internacionalmente, caracterizado pelos autores como mercado de cidades. Moradores, turistas e investidores são os públicos a serem contemplados por meio de ações coordenadas, nas quais está implícito o conceito de planejamento e se faz necessário o uso intenso da comunicação como instrumento viabilizador da gestão pública.

Porém, a simples aplicação das ferramentas de comunicação na gestão pública não assegura a ampliação da participação popular na administração municipal, a aplicação mais equitativa dos recursos em beneficio da coletividade ou a atração de investimentos aptos a impulsionar o desenvolvimento local. Observa-se que a utilização da comunicação por parte dos gestores municipais deve pautar-se nos pressupostos legais previstos em lei, de modo a possibilitar a nova urbanidade formada pela revisão paradigmática da gestão urbana.

Segundo Choay (apud PICCINI, 2003, p. 2), o urbano pode ser entendido como:

[...] um sistema operatório que se desenvolve em todos os lugares: nas cidades e no campo, nas vilas e nos bairros, a partir de redes materiais e imateriais e de um conjunto de objetos técnicos que põem em circulação um mundo de imagens e informações que transformam os vínculos que as sociedades mantêm com o espaço, com o tempo e com os indivíduos.

A reflexão acima descortina os desafios contemporâneos quanto à contínua construção de relações políticas mais inclusivas e democráticas. A existência da comunicação digital altera as relações sociais. Essa realidade está posta e cabe aos pesquisadores e gestores debaterem estratégias para potencializar os recursos digitais em favor do desenvolvimento local, principalmente para superar a dicotomia entre o legal e o real. $\mathrm{O}$ aumento do volume e da circulação de dados 
decorrentes da comunicação digital transforma a forma como o cidadão se relaciona com a cidade. Deste modo, os meios de comunicação desempenham uma função essencial na sociedade contemporânea, pois diversos processos sociais e políticos são desencadeados a partir de relações mediadas, que constituem leituras da realidade, e não propriamente na realidade. Os debates políticos, por exemplo, ocorrem com grande intensidade em ambientes mediados, o que permite afirmar que o equilíbrio do processo democrático depende do acesso equitativo à informação e às mídias.

O Brasil, no que tange a disseminação das inovações tecnológicas, é historicamente caracterizado por uma desigualdade abissal quanto ao acesso aos recursos, principalmente as mídias, demonstrando relações sociais e de poder assimétricas. Prerrogativas legais, como a Lei da Transparência, são marcos institucionais pertinentes a luta contra a desigualdade ao acesso à informação. $\mathrm{O}$ combate e a eliminação dessa desigualdade histórica e estrutural no Brasil têm nos marcos legais um apoio formal adequado a superação da dicotomia entre as determinações constitucionais e a realidade social. A existência do aparato legal favorece a articulação de iniciativas populares no âmbito municipal ou das unidades da federação por acesso à informação, que pode instituir uma dinâmica dialética transformadora da relação entre a cidade legal, a cidade ideal e a cidade real.

Neste sentido, há dados que mostram a formação de uma tessitura comunicacional capaz de sustentar a transformação acima sugerida. A Tabela 1 revela que o acesso à Internet por parte do cidadão comum tem aumentado significativamente nos últimos anos, apesar de menos de $1 / 4$ dos domicílios brasileiros terem acesso à rede, o que é uma barreira a ser superada ainda para se atingir o uso pleno da comunicação digital como instrumento facilitador da gestão participativa em escala municipal.

Tabela 1 - Domicílios com acesso à internet, Brasil, 2005-2009

\begin{tabular}{ccccc}
\hline \multicolumn{4}{c}{ Proporção de domicílios com acesso à internet } & $(\%$ sobre o total de domicílios) \\
\hline $\mathbf{2 0 0 5}$ & $\mathbf{2 0 0 6}$ & $\mathbf{2 0 0 7}$ & $\mathbf{2 0 0 8}$ & $\mathbf{2 0 0 9}$ \\
\hline $12,93 \%$ & $14,49 \%$ & $17 \%$ & $20 \%$ & $24 \%$ \\
\hline
\end{tabular}

Fonte: Adaptado de Comitê Gestor de Internet no Brasil.

A transformação desse parâmetro excludente está vinculada a organização de iniciativas pautadas na esfera da cidade legal, real e ideal, em um processo cujo resultado pode estimular a ruptura em direção às tendências de gestão democrática, que no caso brasileiro estruturam-se em práticas participativas. A negligência do município na efetivação da publicidade de informações aos munícipes e também da formação de meios de participação na gestão municipal ratifica a exclusão histórica da porção majoritária dos brasileiros da gestão da 
cidade. A incorporação do potencial das tecnologias de informação e comunicação descortina a possibilidade de efetivá-las como ferramentas estratégicas relativas à práxis de uma gestão participativa, delineada no marco institucional que é o Estatuto da Cidade.

Destaca-se que a simples utilização de recursos tecnológicos não assegura a realização de uma administração democrática. As tecnologias da informação e comunicação são ferramentas facilitadoras da acessibilidade, sendo, portanto, instrumentais da ação política e subordinadas as relações sociais que estruturam tanto os fluxos de comunicação quanto as relações de poder. Deste modo:

$\mathrm{Na}$ sociedade contemporânea, a opção comunitária está confrontada com dois desafios principais, ambos em aparente conflito: em primeiro lugar, trata-se de aprender com a elite empresarial no que diz respeito à sua estratégia de organizar-se em redes e aumentar, desse modo, a capacidade para a ação coletiva e a cooperação por meio da promoção de confiança e reciprocidade entre os membros das redes; em segundo lugar, trata-se de evitar as tendências de exclusão - muito comuns nas redes empresariais - e garantir procedimentos democráticos e práticas coletivas baseadas em deliberações públicas e interativas, de modo que condições para a promoção do bem comum possam ser efetivamente melhoradas. No contexto de crescentes conflitos sociais e culturais, em uma sociedade cada vez mais complexa e diversificada, e em face de novas e inusitadas potencialidades de criação de redes em função da disseminação dos TICs, os riscos relacionados à segregação, à exclusão e a um possível aumento de conflitos e de intolerância devido à proliferação dessas novas estruturas de rede não devem ser subestimados (FREY, 2003, p. 176).

As observações acima destacadas apontam o complexo potencial dos processos de comunicação pautados nas redes sociais via comunicação digital. Ressalta-se que o conceito de rede social adotado no presente artigo está ancorado na percepção historicamente situada quanto existência de redes sociais precederem a disseminação contemporânea das tecnologias da informação. A articulação dos atores sociais em redes é relativa à elaboração de constructos sociais pertinentes aos meios disponíveis de comunicação que pautam os processos formativos e reprodutores das relações sociais. Deste modo, a efetivação de um modelo de gestão capaz de priorizar a participação de atores sociais de todos os setores da sociedade decorre da competência em tornar mídias digitais instrumentos de superação da histórica barreira que segrega amplos setores da população do exercício do poder. Nesse sentido, a criação e a adoção de terminologias particulares ao novo contexto, a exemplo do termo governo eletrônico, conectado ao uso das recém-disseminadas tecnologias de informação e de comunicação no espectro das atribuições próprias das diferentes esferas de governo, e exercendo a função de instrumental mais ajustado ao ideal de transparência da gestão pública, 
têm que ser observada a partir de um patamar crítico, distante de qualquer veleidade idealista. Tal postura está ancorada na experiência histórica brasileira que mantém, apesar da modernização constante dos processos produtivos e de comunicação, os desequilíbrios sociais. O contexto social brasileiro constitui desafio substancial a incorporação da comunicação digital na administração municipal como instrumento potencializador da gestão democrática e inclusiva. A adoção da tecnologia da informação pautada em mecanismos digitais é fundamental, mas sua adoção como ferramenta administrativa não pode ser uma simples formalidade modernizadora do aparato burocrático. A acessibilidade para o cidadão e a interatividade tem que ser efetivas. Negar o potencial da comunicação digital implica rejeitar a absorção de novos recursos relacionados à oportunidade de romper com a histórica separação entre a maioria da população e o poder público municipal.

A formação da sociedade em rede, baseada na comunicação interativa, apesar da manutenção de grupos políticos adeptos de práticas autoritárias e reprodutoras das estruturas sociais responsáveis por preservar a histórica desigualdade social brasileira, conforma um recurso inovador quanto ao contexto da administração pública. O estimulo a participação política da população por meio das redes e mídias sociais é uma oportunidade ímpar para assegurar a liberdade de expressão e a própria democracia, pois possibilita e assegura a multiplicidade de opiniões. As redes sociais digitais têm o potencial de dinamizar a participação da população nos processos de gestão devido a dois fatores inéditos nas relações entre munícipes e gestores: redução do custo financeiro e a interatividade que permite a superação das barreiras do tempo e da distância. As transformações produzidas mediante a ascensão da comunicação digital potencializam a formação de processos inclusivos de gestão pública. Porém, o uso democrático dos meios de comunicação digital quanto a gestão não é automático. Sua efetivação concerne à mobilização social necessária para garantir que os gestores municipais adotem, de fato, práticas que permitam o acesso da população à administração pública, o que, portanto, corresponde à organização da comunicação entre a administração municipal e os cidadãos com esse objetivo.

Duas premissas pautam a avaliação sobre a aplicação de estratégias pertinentes a aplicação das possibilidades intrínsecas a comunicação digital. A primeira premissa resulta da formulação de Castells (1999) quanto ao potencial relativo à posição social dos grupos economicamente predominantes. Tais grupos sociais, historicamente, têm mais acesso e, portanto, controle das inovações tecnológicas, e as aplicam para preservar e exercer seu poder em relação aos demais grupos sociais. Cabe ao poder público realizar ações para aumentar a inclusão social digital e reverter essa tendência. A aplicação dessa premissa é essencial para a realização do potencial pertinente à comunicação digital. Já a segunda premissa denota os efeitos da tecnologia sobre o desenvolvimento humano. O processo de acesso à informação e a comunicação da população com os administradores 
públicos evidencia o grau de liberdade política usufruída pelos cidadãos, o que pode possibilitar ou não a inclusão social. Para Sen (2000), a liberdade política potencializa o desenvolvimento humano. Segundo esse autor, a liberdade de informação e expressão caracteriza as sociedades desenvolvidas e é um fator relacionado ao efetivo desenvolvimento humano, por possibilitar a transparência da gestão pública.

O Estatuto da Cidade (2001), resultado das mudanças promovidas com a Constituição de 1988, busca estabelecer um novo patamar de efetivação de políticas públicas no espectro municipal, ao atribuir para os municípios a responsabilidade quanto a promoção da gestão participativa. A consolidação do Estatuto da Cidade no âmbito legal estimulou a participação ativa dos munícipes na gestão dos municípios brasileiros. Historicamente, a formação do Estatuto das Cidades processou-se quando os meios de comunicação restringiam-se a um formato convencional, produtor de relações passivas entre os munícipes e os gestores, pois pautado em fluxos de comunicação não interativos. O secular distanciamento do poder executivo brasileiro em relação à população, associada à cultura autoritária aprofundada durante a ditadura militar, conformaram uma estrutura de poder resiliente à gestão participativa. A comunicação digital implica a possibilidade ímpar de transformar o padrão brasileiro de relações de poder entre os cidadãos e os gestores. Entretanto, Castells (1999) salienta que as relações sociais desiguais são fundamentadas pelo desequilíbrio quanto ao acesso aos recursos sociais necessários à apropriação da profunda inovação tecnológica. Portanto, cabe aos gestores públicos buscar meios de promover a participação mais abrangente dos múltiplos segmentos sociais por meio da tecnologia da informação para colaborar com o rompimento da concentração de poder e recursos. Esse dilema somente pode ser superado por meio da práxis política inclusiva. Historicamente, constitui-se um cenário inédito para a participação popular. Somente uma ação dupla, de disponibilização dos recursos relativos a tecnologia da informação, aliada a cobrança dos cidadãos por sua efetivação, garantirá a efetivação das novas possibilidades de inclusão democrática.

A ascensão da comunicação digital possibilita a convergência entre os cidadãos e os gestores municipais. Para Frey (2003), a constituição de formas de comunicação relacionadas ao aumento da utilização democrática da comunicação digital para a efetivação das ferramentas de estímulo da participação política local é estratégica. Entretanto, na eventualidade dos cidadãos não possuírem os recursos necessários para usar a comunicação digital para acessar o poder executivo municipal, não será possível a ampliação da liberdade política dos munícipes. Assim, é ineficaz a adoção das ferramentas digitais na administração municipal sem a existência dos recursos necessários à efetiva participação popular na gestão pública municipal.

A comunicação digital implica na constituição de redes sociais virtuais que ultrapassam as limitações espaciais e temporais do território pertinentes à experiência social atual. Neste contexto ocorre o estímulo à organização de grupos 
estruturados a partir de demandas concretas ao poder público municipal. Todavia, a estruturação de redes sociais vinculadas à gestão tem de ser planejada e efetivada objetivando a inclusão dos grupos sociais que representam a complexidade e a diversidade pertinente à sociedade. A construção dos sites oficiais das prefeituras municipais mediante plataformas amigáveis e interativas que facilitem a navegação, com a disponibilização das tecnologias pertinentes à formação das redes sociais, é um recurso basilar para favorecer a participação da população na gestão pública local. Sob esse prisma, é fundamental considerar que "[...] quando uma sociedade começa a se modernizar, um dos primeiros sinais de desenvolvimento é a dilatação dos canais de comunicação", conforme a observação assertiva de Schramm (1970, p. 129).

\section{Método}

A pesquisa caracteriza-se como descritiva quanto ao objetivo, de abordagem qualitativa, com delineamento documental. A área de estudo é a recém-criada Região Metropolitana do Vale do Paraíba - SP, Brasil. Tal recorte geográfico justifica-se pelo desafio de pensar o desenvolvimento a partir da perspectiva da região, o que implica a articulação entre as esferas federal, estadual e local, bem como da sociedade, visto que, em função do escopo de atuação de cada um desses níveis de governo, buscam-se soluções que contemplem os agentes e atores envolvidos. Essa articulação se apresenta na Região Metropolitana do Vale do Paraíba, criada pela Lei Complementar Estadual No 1.166, de 9 de janeiro de 2012, que formaliza a integração regional e permite, a partir das premissas legais que se aplicam às regiões metropolitanas, pensar e agir regionalmente em prol do desenvolvimento.

Os documentos consultados consistem nos sites oficiais dos municípios dessa região metropolitana. A coleta de dados foi realizada no período de janeiro a abril de 2012. Os critérios de análise do conteúdo dos sites foram delimitados pelos autores, a saber: disponibilização dos contatos diretos dos gestores públicos; disponibilização de serviços on-line; disponibilização das contas públicas municipais; comunicado sobre mecanismos de participação formalmente institucionalizados; públicos contemplados; uso de mídias sociais para ampliação do diálogo direto com o cidadão; disponibilização das leis municipais, inclusive plano diretor; informações sobre as ações referentes à gestão municipal. 
Quadro 1 - Critérios de análise

\begin{tabular}{|l|l|}
\hline \multicolumn{1}{|c|}{ Critérios } & \multicolumn{1}{c|}{ Justificativa } \\
\hline Contatos & $\begin{array}{l}\text { O contato facilitado é compreendido como forma de ampliar o } \\
\text { diálogo entre munícipes e governo. }\end{array}$ \\
\hline Serviços on-line & $\begin{array}{l}\text { A oferta de serviços on-line representa facilitação do acesso aos } \\
\text { serviços, muitos dos quais incluídos nas liberdades instrumentais } \\
\text { apontadas por Sen (2000). }\end{array}$ \\
\hline $\begin{array}{l}\text { Consulta às contas } \\
\text { públicas }\end{array}$ & $\begin{array}{l}\text { A disponibilização de contas públicas possui relação direta com a } \\
\text { transparência, também apontada por Sen (2000). }\end{array}$ \\
\hline $\begin{array}{l}\text { Comunicado } \\
\text { mecanismos } \\
\text { participação }\end{array}$ & $\begin{array}{l}\text { A divulgação de instrumentos institucionalizados de participação } \\
\text { popular na gestão pública, tais quais audiências públicas, é um } \\
\text { indicador de gestão democrática. }\end{array}$ \\
\hline $\begin{array}{l}\text { Públicos } \\
\text { contemplados }\end{array}$ & $\begin{array}{l}\text { O diálogo com públicos distintos demonstra o reconhecimento da } \\
\text { diversidade dos atores sociais. }\end{array}$ \\
\hline $\begin{array}{l}\text { Uso de redes sociais, } \\
\text { blogs }\end{array}$ & $\begin{array}{l}\text { Essencialmente interativos e livres de controle de conteúdo, as } \\
\text { redes sociais e blogs concretizam o diálogo equitativo entre as } \\
\text { partes. }\end{array}$ \\
\hline $\begin{array}{l}\text { Disponibilização de } \\
\text { legislação }\end{array}$ & $\begin{array}{l}\text { Acesso e direito à informação é elemento essencial para o } \\
\text { desenvolvimento, conforme Sen (2000). }\end{array}$ \\
\hline $\begin{array}{l}\text { Informações sobre a } \\
\text { gestão }\end{array}$ & $\begin{array}{l}\text { O detalhamento das ações relaciona-se também com a transparência } \\
\text { da gestão. }\end{array}$ \\
\hline Observações & Destaque para alguma especificidade do site \\
\hline
\end{tabular}

Fonte: Elaborado pelos autores.

Enfatiza-se que os aspectos selecionados condizem com as possibilidades tecnológicas existentes na atualidade para a comunicação digital e que podem se configurar como ferramentas facilitadoras para o exercício de mecanismos participativos, bem como são essenciais para a disponibilização de informações sobre a gestão pública.

\section{Resultados e discussão}

O quadro abaixo apresenta os resultados da microrregião de Bananal, que compõe a região metropolitana do Vale do Paraíba e Litoral Norte. Para otimizar o uso do espaço em obediência aos limites do artigo, apenas o quadro abaixo será apresentado. A macrorregião é composta por cinco microrregiões que, juntas, têm 39 municípios. A apresentação dos dados de todos os municípios tornar-se-ia muito extensa. O quadro abaixo demonstra o uso dos critérios acima apresentados e a análise foi replicada para a avaliação de cada microrregião e respectivos municípios. 
Quadro 2 - Análise dos sites dos municípios da microrregião de Bananal

\begin{tabular}{|c|c|c|c|c|c|}
\hline Município & Arapeí * & Areias & Bananal & $\begin{array}{c}\begin{array}{c}\text { São José do } \\
\text { Barreiro }\end{array} \\
\end{array}$ & Silveiras \\
\hline Contatos & $\begin{array}{l}\text { Contato geral } \\
\text { Setor de } \\
\text { comunicação }\end{array}$ & $\begin{array}{l}\text { Disponibilização } \\
\text { dos e-mails } \\
\text { diretos dos } \\
\text { gestores } \\
\text { públicos }\end{array}$ & $\begin{array}{l}\text { Um único e- } \\
\text { mail geral }\end{array}$ & $\begin{array}{l}\text { Apenas formu- } \\
\text { lário de envio } \\
\text { de e-mail para } \\
\text { Administrativo, } \\
\text { Comunicação e } \\
\text { Turismo }\end{array}$ & $\begin{array}{l}\text { Um único e- } \\
\text { mail geral } \\
\text { com } \\
\text { formulário } \\
\text { para envio } \\
\text { de e-mail }\end{array}$ \\
\hline $\begin{array}{l}\text { Serviços on- } \\
\text { line }\end{array}$ & Não disponíveis & $\begin{array}{l}\text { Apenas a lista de } \\
\text { departamentos } \\
\text { responsáveis } \\
\text { pelos serviços } \\
\text { básicos }\end{array}$ & $\begin{array}{l}\text { Inscrição on- } \\
\text { line para } \\
\text { concurso }\end{array}$ & $\begin{array}{l}\text { Banco de } \\
\text { currículos } \\
\text { Vagas de } \\
\text { empregos }\end{array}$ & Não \\
\hline $\begin{array}{l}\text { Consulta às } \\
\text { contas } \\
\text { públicas } \\
\text { (Transparên- } \\
\text { cia) }\end{array}$ & $\begin{array}{l}\text { Informações } \\
\text { desatualizadas. } \\
\text { Mais recente de } \\
2006\end{array}$ & $\begin{array}{l}\text { Disponíveis e } \\
\text { atualizadas }\end{array}$ & $\begin{array}{l}\text { Link existente } \\
\text { mas conteúdo } \\
\text { indisponível } \\
\text { na data da } \\
\text { consulta }\end{array}$ & Não há & $\begin{array}{l}\text { Disponíveis } \\
\text { os } \\
\text { balancetes, } \\
\text { relação de } \\
\text { cargos e } \\
\text { salários, } \\
\text { orçamentos }\end{array}$ \\
\hline $\begin{array}{l}\text { Mecanismos } \\
\text { participação }\end{array}$ & $\begin{array}{l}\text { Não há. Apenas } \\
\text { o Fale conosco }\end{array}$ & $\begin{array}{l}\text { Apenas a } \\
\text { disponibilização } \\
\text { dos e-mails }\end{array}$ & $\begin{array}{l}\text { Apenas } \\
\text { cadastro para } \\
\text { envio de e- } \\
\text { mail }\end{array}$ & $\begin{array}{l}\text { Apenas } \\
\text { cadastro para } \\
\text { envio de e-mail }\end{array}$ & $\begin{array}{l}\text { Livro de } \\
\text { visitas para } \\
\text { deixar } \\
\text { comentário } \\
\text { on line, no } \\
\text { entanto com } \\
\text { falha de } \\
\text { envio e } \\
\text { visualização } \\
\text { na data da } \\
\text { consulta } \\
\end{array}$ \\
\hline $\begin{array}{l}\text { Públicos } \\
\text { contemplados }\end{array}$ & $\begin{array}{l}\text { Turistas } \\
\text { Munícipes }\end{array}$ & $\begin{array}{l}\text { Turistas } \\
\text { Munícipes }\end{array}$ & $\begin{array}{l}\text { Turistas } \\
\text { Munícipes }\end{array}$ & Munícipes & Munícipes \\
\hline $\begin{array}{l}\text { Uso de redes } \\
\text { sociais, blogs }\end{array}$ & Não & Não & Não & $\begin{array}{l}\text { Twitter } \\
\text { Facebook }\end{array}$ & Não \\
\hline $\begin{array}{l}\text { Disponibiliza- } \\
\text { ção de } \\
\text { legislação }\end{array}$ & Não & $\begin{array}{l}\text { Algumas, } \\
\text { relativas à } \\
\text { questão } \\
\text { orçamentária } \\
\end{array}$ & Não & Não & $\begin{array}{l}\text { Disponíveis } \\
\text { para } \\
\text { consulta por } \\
\text { ano }\end{array}$ \\
\hline $\begin{array}{l}\text { Informações } \\
\text { sobre a gestão }\end{array}$ & $\begin{array}{l}\text { Não há. Links } \\
\text { com a estrutura } \\
\text { administrativa, } \\
\text { porém sem } \\
\text { informação }\end{array}$ & $\begin{array}{l}\text { Algumas } \\
\text { notícias e fotos } \\
\text { de ações } \\
\text { realizadas, com } \\
\text { poucas } \\
\text { informações }\end{array}$ & $\begin{array}{l}\text { Apresenta } \\
\text { algumas } \\
\text { notícias no } \\
\text { link Retros- } \\
\text { pectiva } 2010 . \\
\text { Retrospectiva } \\
2009 \text { "em } \\
\text { construção" }\end{array}$ & $\begin{array}{l}\text { Apenas link de } \\
\text { notícias }\end{array}$ & Não \\
\hline
\end{tabular}

Fonte: elaborado pelos autores.

* Grande destaque a informações turísticas 
Observa-se que todos os municípios da região metropolitana tornam públicos conteúdos relativos à gestão municipal mediante o site oficial do governo municipal, porém, com particularidades que os distinguem no uso dos recursos digitais. Em uma avaliação geral acerca dos dados obtidos, fica evidente a disponibilização escassa de recursos que favoreçam a participação dos cidadãos. Os sites que apresentam melhor construção sob o prisma do acesso à informação propiciam serviços limitados para os munícipes, o que indica a preocupação de apenas satisfazer as determinações legais relativas à transparência e comunicação com o público.

A análise dos sites revelou uma característica comum quanto aos municípios da região metropolitana abordada: a maioria dos municípios se comunica somente com os munícipes e poucos com os turistas. Esse traço revela a ausência de uma visão estratégica acerca do potencial das tecnologias da comunicação. Há algumas exceções que merecem destaque, mas no conjunto dos municípios da região metropolitana há a carência de uma estratégia mais complexa relativa a interação entre a sociedade e a administração pública local. Na microrregião de Campos do Jordão destacam-se dois municípios. São Bento do Sapucaí e Campos do Jordão são os únicos a propiciar informações aos empresários e/ou possíveis investidores, demonstrando uma abertura ao dialogo efetivo com o público externo. Outro aspecto relevante quanto a Campos do Jordão é a disponibilização de conteúdo aos servidores, o que evidencia uma percepção de administração pública mais refinada ao considerar o público interno da respectiva prefeitura municipal. Essa postura é muito pertinente do ponto de vista da transparência e da democracia, tendo em vista que Campos do Jordão tem como principal atividade econômica o turismo, e não utiliza de modo absoluto essa característica em seu site. Tal característica salienta parcimônia na produção e na apresentação das informações.

Significativamente, o mesmo cuidado ocorre em outros municípios turísticos inseridos na microrregião de Caraguatatuba. Os municípios de São Sebastião e de Caraguatatuba apresentam bom conteúdo disponibilizado para os servidores públicos. A coincidência entre três municípios com perfil turístico no que tange a produção de conteúdo específico para os servidores e turistas aponta para um aspecto estrutural, a atividade turística, que pode ter estimulado a preocupação em tornar os respectivos sites mais atraentes para o visitante e tal preocupação incidiu sobre os demais serviços oferecidos. Essa hipótese carece de uma verificação mais cuidadosa quanto à utilização desse conteúdo por parte do público interno. Ainda em relação à microrregião de Caraguatatuba, nota-se a apresentação de conteúdo informativo significativo nos respectivos sites. Todos os integrantes da microrregião têm atividade turística significativa, o que corrobora a necessidade de investigações específicas dedicadas a essa realidade.

Entre os públicos que os sites municipais poderiam contemplar desperta atenção a ausência de um grupo em particular: a imprensa. Sua falta revela uma deficiência 
crônica na região quanto à adoção do marketing aplicado às cidades, principalmente sob a perspectiva de que um relacionamento positivo com este setor é uma premissa fundamental para consolidar o posicionamento da administração municipal e, portanto, da cidade, com os públicos interno e externo. De acordo com as observações anteriores, o processo político atual é mediado por parâmetros comunicacionais. Os recursos interativos limitam-se, na maioria das cidades, ao oferecimento de formulário para envio de e-mails. Poucas cidades utilizam as redes sociais, recurso que, devido suas especificidades, favorece maior interação e é um meio de acesso mais ágil em relação aos gestores municipais.

Em relação à disponibilização das contas públicas, observou-se que muitos municípios não aplicam a determinação legal ou não realizam a atualização constante das informações relativas à transparência da gestão pública. Esse cenário permite questionar as administrações municipais que procedem desta maneira sob o prisma da negligência ou do conluio relativo à efetivação de um procedimento que aparentemente cumpre a prerrogativa legal, mas que efetivamente é aplicado para obstruir o acesso do cidadão às contas públicas. A existência da determinação legal não implica a sua execução correta. Nota-se o mesmo problema quanto a divulgação da legislação municipal, particularmente quanto a atualização. O acesso à informação pública transparente constitui parâmetro da gestão democrática, mesmo que realizado de modo limitado. Os municípios avaliados cumprem as determinações legais de modo parcial e estão em uma situação dúbia, embora não autoritária. Apesar das deficiências citadas, é preciso destacar que, em comparação com o passado recente, a disponibilização de informações acerca da gestão municipal, ainda que limitada, é indicativa do progresso em direção à transparência propugnada por Sen (2000) como fator estratégico para o desenvolvimento humano.

O cenário acima descrito revela que a divulgação de conteúdo nos sites municipais limita-se, na maioria dos casos, a efetivar apenas o mínimo previsto na legislação, evidenciando certa apatia dos mecanismos de participação popular no exercício da gestão pública. A perspectiva adotada para o diagnóstico desta conjuntura não é fiscalizatória. Antes, trata-se de pensar o exercício da gestão publica sob a perspectiva das relações de poder social e historicamente constituídas. A tradição política brasileira pauta-se pelo paternalismo. Constatou-se nessa pesquisa que os serviços de comunicação das prefeituras municipais da região ainda estão pautados por esse traço estrutural e estruturante da sociedade brasileira. Evidentemente, a disponibilização de serviços e informações ao público possibilita condições para que o cidadão se posicione em relação às ações do governo municipal. Mas esse posicionamento não depende das ações do poder executivo. Cabe aos cidadãos superarem a postura passiva que permeia a sociedade brasileira, avançando, inclusive, além do simples papel fiscalizador. As possibilidades legais expressas no Estatuto das Cidades e na Lei da Transparência propiciam um cenário inédito aos cidadãos quanto ao exercício da sua corresponsabilidade política. O processo 
político é constante e é necessário superar a miopia que restringe o seu exercício somente ao período das eleições.

A avaliação realizada indica que o acesso aos serviços municipais oferecidos por meio dos sites das prefeituras municipais é muito restrito quando em comparação as possibilidades das tecnologias disponíveis, propiciando um acesso muito restrito dos cidadãos aos serviços básicos. Outro aspecto detectado na pesquisa refere-se à impossibilidade de detectar um padrão de uso e de aplicação da comunicação digital pelos municípios da macrorregião. $O$ potencial das tecnologias da informação não é explorado adequadamente no cenário contemporâneo da região.

A exceção neste cenário é o município de São José dos Campos, localizado na microrregião homônima. O site do município é voltado à prestação de serviços aos cidadãos e também a investidores interessados no potencial da cidade. Denota-se que São José dos Campos é a principal cidade da região metropolitana do Vale do Paraíba e do Litoral Norte. Sua posição é importante por constituir referência para as demais prefeituras da região e por estabelecer um patamar que, se não a qualifica como vanguarda da realização de ações políticas democráticas quanto à ampliação da gestão para a participação popular, aponta uma trajetória nessa direção. Embora a prestação de serviços com foco no atendimento das necessidades do cidadão seja uma obrigação da gestão pública, as tecnologias da comunicação denotam possibilidades mais inclusivas sob o prisma político. Portanto, a inclusão democrática no gerenciamento da cidade supera o oferecimento de serviços e aponta a necessidade da efetiva participação política.

Verificou-se grande disparidade entre os municípios no que se refere ao cumprimento da prerrogativa legal de disponibilização de informações sobre a gestão pública aos cidadãos. Alguns municípios, claramente, apenas cumprem o mínimo previsto em lei, outros chegam a negligenciar a disponibilização das informações básicas obrigatórias e outros buscam fazer uso da comunicação como uma ferramenta facilitadora da relação entre o governo e os munícipes, fundamentada no conceito de democracia participativa. Outra categoria ainda faz uso do canal para evidenciar um discurso que tangencia o partidário.

Significativamente, os sites dos municípios que compõem a região metropolitana do Vale do Paraíba não a destacam. Inexiste a apresentação da região metropolitana e suas possibilidades de ensejar o desenvolvimento regional que pode vir a beneficiar cada município que a integra. Esse cenário revela uma postura bairrista que perpassa a condução das administrações locais. A ausência de uma integração mais efetiva na região metropolitana é preocupante, pois sua criação justifica-se em razão da necessidade de ajustar políticas de desenvolvimento balizadas por princípios relacionados à sustentabilidade sócia e ambiental e, também, pela otimização da aplicação dos recursos públicos. 
Tal diagnóstico permite reforçar a necessidade de capacitação de gestores municipais e evidencia a desigualdade estrutural da gestão dos municípios da nova região metropolitana. Elabora-se a reflexão de que a recente formação da região metropolitana, em janeiro de 2012, integrará os governos municipais, o que poderá ter reflexo positivo nos municípios menos estruturados. As prerrogativas legais que obrigam o município a disponibilizar informações ao munícipe, tal qual a Lei da Transparência, que se refere à disponibilização das contas públicas à sociedade, demonstram uma clara relação entre as instâncias federal e estadual sobre o município, em uma necessária articulação entre os poderes para a busca do desenvolvimento regional e local.

\section{Considerações finais}

O presente trabalho objetivou realizar uma análise acerca do uso das tecnologias da comunicação aplicadas a gestão municipal sob o prisma da divulgação de informações, transparência e promoção da participação dos cidadãos na gestão municipal correlacionados aos princípios da democracia inclusiva e participativa, o que é fundamental tanto para o desenvolvimento local quanto regional. Deste modo, a investigação que subsidiou o artigo concentrou-se na pesquisa sobre como os municípios provem o acesso da sociedade a informações relativas a gestão pública municipal, mediante a utilização das tecnologias da comunicação digital. Buscou-se entender como ocorre o uso da comunicação digital para perceber se existe, na área abordada pela investigação, o reforço dos preceitos da democracia participativa característica do panorama legal da gestão pública municipal brasileira. Nota-se que houve o cuidado de evitar uma postura ingênua, que atribui à existência do marco legal a sua efetivação imediata. Entende-se que existe uma diferença ente o real, o legal e o ideal. Essa postura permeou a análise dos dados coletados.

Observou-se que os sites dos municípios que compõem cada microrregião avaliada, em razão dos recursos tecnológicos existentes, absorveram escassos mecanismos que têm o potencial de promover a participação política da população. Entretanto, não é adequado negligenciar o progresso representado pela publicação de informações relativas à administração municipal. Esse novo cenário pode ser caracterizado como o inicio da superação das relações autoritárias que permeiam a sociedade brasileira quanto ao acesso à gestão municipal. É correto afirmar que essa trajetória ainda é incipiente, mas o marco legal abordado neste artigo implica na existência de parâmetros adequados à busca por sua realização. A mobilização política da população pode garantir sua efetivação. Aliás, o alcance de um novo cenário na gestão municipal quanto aos preceitos da democracia participativa não depende apenas dos gestores municipais. Essa é uma trajetória complexa. O marco legal favorece a mobilização popular. A obrigatoriedade da transparência e 
da constituição de canais de participação do cidadão na gestão pública tem como correspondente a formulação e execução de uma postura ativa por parte dos munícipes.

Apesar das deficiências detectadas tanto no conteúdo quanto nos mecanismos disponibilizados nos sites das prefeituras municipais, principalmente quanto a parcialidade das informações, incompletude dos conteúdos ou ausência de recursos mais amigáveis para o acesso a determinadas informações, como por exemplo, as contas públicas, a identificação dos gestores municipais e a disponibilização da legislação municipal são características que apontam uma trajetória, ainda que inconclusa, em direção à transparência. Destaca-se que o objeto avaliado neste artigo não constitui variável única para diagnosticar a existência ou inexistência da gestão democrática em cada município incluído na pesquisa. Contudo, é inegável o papel da comunicação governamental com o cidadão para a efetivação da gestão participativa. Sem sua efetivação, o munícipe fica restrito em relação ao direcionamento das demandas quanto ao acesso aos serviços públicos e a efetiva participação nos processos decisórios. Neste cenário, o ambiente digital configura-se como a mídia pertinente para efetivar o acesso irrestrito da população ao poder público municipal.

\section{Referências}

CASTELLS, M. A sociedade em rede. (Vol.1: A era da informação: economia, sociedade e cultura). São Paulo: Paz e Terra, 1999.

COMITÊ Gestor de Internet no Brasil. Disponível em: <http://www.cetic.br/usuarios/tic/2009-total-brasil/index.htm>. Acesso em: 12 abr. 2010.

BRASIL. Estatuto da cidade. Lei Federal No 10.257 de 10 de julho de 2001.

FREY, Klaus. Desenvolvimento sustentável local na sociedade em rede: o potencial das novas tecnologias de informação e comunicação. Revista de Sociologia e Política, Curitiba, n. 21, nov. 2003. Disponível em: $<$ http://www.scielo.br/scielo.php?script=sci_arttext\&pid=S010444782003000200011\&lng=pt\&nrm=iso > . Acesso em: 04 mar. 2012.

KOTLER, P. et al. Marketing de lugares. São Paulo: Pearson, 2005.

PICCINI. M. Sobre a comunicação nas grandes cidades. Opinião Pública. vol. IX, n. 2, p. 1-19, out. 2003. 
REZENDE, D. A; FREY, K. BETINI, R. C. Governança e democracia eletrônica na gestão urbana. Buscalegis, s/d. Disponível em: $<$ http://www.buscalegis.ufsc.br/revistas/index.php/buscalegis/article/viewFile/ 6009/5578> Acesso em: 28 mar. 2010.

SCHRAMM, W. Comunicação de massa e desenvolvimento. Rio de Janeiro: Bloch, 1970.

SEN, A. Desenvolvimento como liberdade. São Paulo: Companhia das Letras, 2000.

Endereço para correspondência:

Moacir José dos Santos - santos.mj@ig.com.br

R. Expedicionário Ernesto Pereira, Portão 3

12030-320 Taubaté/SP, Brasil

Monica Franchi Carniello - monicafcarniello@gmail.com

R. Expedicionário Ernesto Pereira, Portão 3

12030-320 Taubaté/SP, Brasil

Edson Aparecida de Araújo Querido Oliveira - edsonaaqo@gmail.com

R. Expedicionário Ernesto Pereira, Portão 3

12030-320 Taubaté/SP, Brasil 